\title{
Advanced Teaching Methods Application and its Benefits in Descriptive Geometry at the Faculty of Civil Engineering and Architecture in Niš
}

\author{
Sonja KRASIĆ, Petar PEJIĆ, Snežana STOJILJKOVIĆ, Mila DOSKOVIĆ, Zlata TOŠIĆ
}

\begin{abstract}
Teaching tools, such as computer drawings in lecture templates, "step by step" presentations, Android application, got introduced so as to improve teaching process quality in Descriptive geometry subject, at the Faculty of Civil Engineering and Architecture in Niš. Advanced teaching methods in practice classes, and on-thescreen video beam projected "step by step" presentations were available only to half of the enrolled students (experimental group -the EG), while the rest attended the practice classes deploying classical teaching methods, and manual drawings on the blackboard (control group -the CG). Deliberation of data on previous education and intellectual capabilities of students involved proved that the groups do not differ. Comparative analysis of the final results in academic year of 2016/17 indicated that in the EG students there was a higher knowledge of the subject matter, and higher exam pass rate. The conclusion is that the application of the advanced teaching methods makes learning and teaching process more successful, thus their usage in the future is recommended.
\end{abstract}

Keywords: advanced teaching methods; classical teaching methods; Descriptive Geometry; FCEA University of Niš; final results; university students

\section{INTRODUCTORY REMARKS}

Descriptive geometry is consequential scientific discipline at technical faculties, which not only enables the communication among future engineers, but also advances their spatial capacities. $[6,7,22,24]$ This scientific discipline examines methods of presenting threedimensional space on a two-dimensional medium (paper or screen). It is of great importance for students to adopt through-the-drawings method of communication, at the very beginning of their study. Students must be equipped with both the theoretical and the practical knowledge for subsequent and other courses. [1,24] With the advent of computers, at many technical faculties, the classical approach in teaching Descriptive geometry subject has been neglected. However, the introduction of computer aided (CA) teaching process for space representation purposes must be carried out with great caution. [22] From a didactic point of view, the classical methods in use for teaching Descriptive geometry cannot be easily replaced. It was a gradual, and "step by step" problem solving carried out in teaching this subject, which has utilised the classical drawing method on the blackboard for a long period of time. [1] Introduction of modern and easy to operate electronic tools and instruments facilitates the work of students in Descriptive geometry classes. Precision and speed, the advantages brought in by the computers and mobile devices, are impressively helpful in mastering the teaching process. [1,22] Applying these tools in modern teaching, while using didactic principles characteristic of classical teaching process, is useful.

\section{ADVANCED TEACHING METHODS IN DESCRIPTIVE GEOMETRY COURSE: EXPERIENCE FROM THE UNIVERSITY OF NIŠ}

\subsection{Introducing Advanced Teaching Methods at the Faculty} of Civil Engineering and Architecture

Let us begin with a short overview of the changes done in the previous 10 years, to improve teaching methods for Descriptive geometry. As for the Descriptive geometry (the DG) subject, at the Faculty of Civil Engineering and Architecture (The FCEA) University of Niš, at the study program of Civil Engineering (CE), there were no recent changes when it comes to curriculum, number of classes and the examination method. Three-dimensional space was presented on a two-dimensional media, blackboard or paper, in a manual way, both during the lectures and in practice classes. The method of presentation, being the only variable, gets complemented by the advanced methods, encompassing usage of computers, internet and mobile phone applications. In the teaching process, modern tools have been introduced, in accordance with the educational, psychological, and social requirements of the general public. [12] For that reason, this is the adequate period for conducting analysis of the success rate demonstrated by the students attending the DG course at study program of the CE (Tab. 1). One of The Bologna Declaration tendencies is the introduction of advanced methods into teaching process in order to improve the quality of the knowledge acquired, which is to be shown in the final results. The increase in the pass rate, i.e. the percentage of successfully finished exams (pass rate), and in the average grade in exams can be considered as indicators of teaching quality improvements.

Table 1 The percentages of students' passing the exam in periods of academic years from 2005/06 to 2016/17 (Source: Krasic et al. 2018)

\begin{tabular}{|c|c|c|c|c|c|c|c|c|c|c|}
\hline $\begin{array}{c}\text { Number of } \\
\text { enrolled students }\end{array}$ & 134 & 116 & 124 & 124 & 140 & 141 & 115 & 95 & 90 & 95 \\
\hline Enrolment year & $2006 / 07$ & $2007 / 08$ & $2008 / 09$ & $2009 / 10$ & $2010 / 11$ & $2011 / 12$ & $2012 / 13$ & $2013 / 14$ & $2014 / 15$ & $2016 / 17$ \\
\hline I period & $7.5 \%$ & $18.1 \%$ & $25.8 \%$ & $37 \%$ & $27.9 \%$ & $31.2 \%$ & $22.6 \%$ & $25.3 \%$ & $44.5 \%$ & $27.0 \%$ \\
\hline II period & $17.9 \%$ & $12.1 \%$ & $25.0 \%$ & $10.5 \%$ & $5.0 \%$ & $18.6 \%$ & $36.5 \%$ & $12.6 \%$ & $17.8 \%$ & $24.7 \%$ \\
\hline III period & $20.1 \%$ & $24.1 \%$ & $8.9 \%$ & $11.3 \%$ & $22.1 \%$ & $12.0 \%$ & $6.1 \%$ & $7.4 \%$ & $4.4 \%$ & $7.9 \%$ \\
\hline IV-VI period & $3.7 \%$ & $2.6 \%$ & $2.4 \%$ & $6.5 \%$ & $9.3 \%$ & $7.0 \%$ & $3.5 \%$ & $3.2 \%$ & $3.3 \%$ & $15.7 \%$ \\
\hline Passed & $49.2 \%$ & $56.9 \%$ & $62.1 \%$ & $65.3 \%$ & $64.3 \%$ & $68.8 \%$ & $68.7 \%$ & $48.5 \%$ & $70.0 \%$ & $75.3 \%$ \\
\hline Not passed & $50.8 \%$ & $43.1 \%$ & $37.9 \%$ & $34.7 \% \%$ & $35.7 \%$ & $31.2 \%$ & $31.5 \%$ & $51.5 \%$ & $30.0 \%$ & $24.7 \%$ \\
\hline
\end{tabular}


Since the academic year of $2009 / 10$, the teacher and teaching assistants of the course took actions to facilitate the learning process with the students.

1) In 2009, it was introducing the lecture templates.

2) In 2012, it was introducing gradual, step-by-step manner graphical tasks on the computer.

3) In the academic year of $2013 / 14$, it was introducing step-by-step graphical tasks Android application.

4) In the 2014/15 academic year advanced method practice classes were introduced.

After the introduction of the said advanced teaching methods, significantly larger number of students $(44.5 \%)$ passed the exam in the first term in academic year of $2014 / 15$ and, consequently, in all other periods $(75.3 \%)$ in the 2016/17 academic year (Tab. 1), as shown by the analysis conducted.

\subsubsection{Lecture Templates}

The lecture templates (Fig. 1) contain the basics of a task, which was to be completed manually by the students, using the material presented by the teacher at the classes. Lecture templates were computer-made using AutoCAD and Corel Draw software.

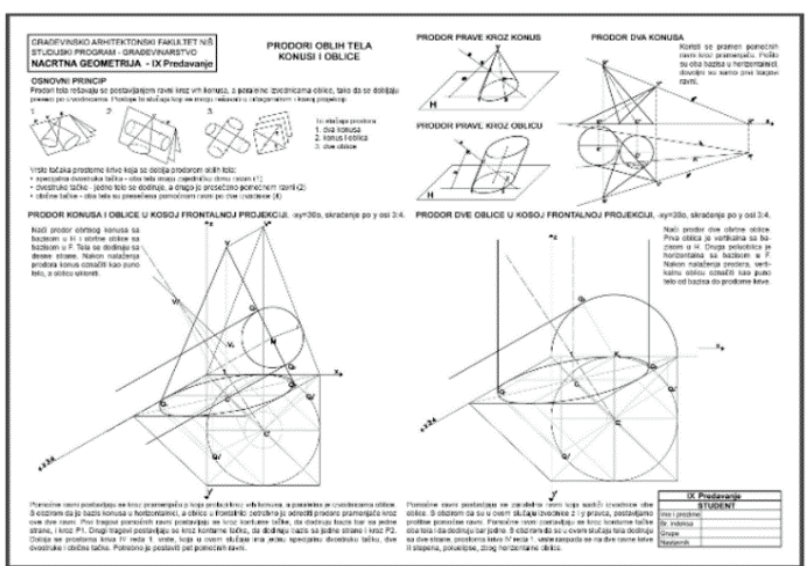

Figure 1 Lecture IX template (Source: Krasic et al. 2018)

The lecture templates have been designed for 12 units within the curriculum. They proved to be extremely useful, since they reduced the need for manual work of students, which in return allowed them to focus on understanding the essential part of the problem at the classes. Apart from the graphics, the templates also contain textual explanations related to the topic of the teaching unit addressed at the lectures.

\subsubsection{Computer Designed "Step By Step" Graphical Tasks}

Gradual tasks-solving didactic method, normally used in the classical practice classes, was the approach transposed when utilizing Corel DRAW computer program in creating step-by-step graphical tasks. PowerPoint presentations got created for each graphical task contained in an individual exercise. All 13 presentations were then uploaded to the web site of the Faculty of Civil Engineering and Architecture in Niš (http://rc5.gaf.ni.ac.rs/dec/viscom/ system/index.php).
Each step in the drawing is followed by the matching slide of the presentation, and it is presented with a clear marking of the points and straight lines used for solving the task (Fig. 2). Some steps have a textual explanation. When using the presentation, the slides can be played back, in case the students need a better explanation of the task solving process. In case that a student fails to complete the graphical task during the class, he/she can use the presentation at the Faculty site and do it at home.

Graphical tasks, designed as "step-by-step" on presentations, can be used by students in preparing for the examination.
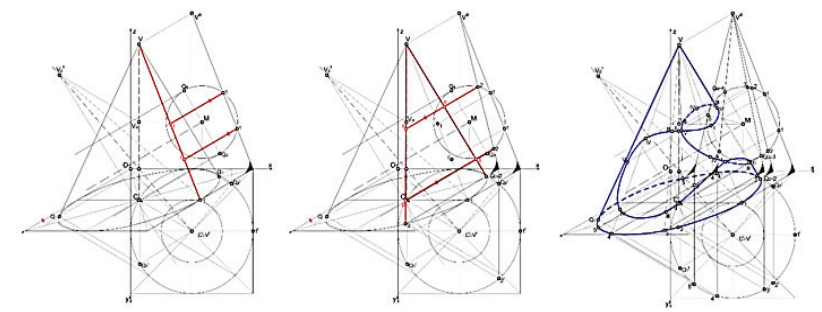

Figure 2 XI "step by step" graphical task (Source: Krasic et al. 2018)

\subsection{3 "Step-By-Step" Android Application for Graphical Tasks}

The application unifies all 13 "step-by-step" graphical tasks and facilitates their usage on smart portable devices with Android operative system (Fig. 3). The advantage of this application is its accessibility to all who use such devices, and it can be downloaded for free https://www.dropbox.com/s/5iru0h3db11f1mb/NG.apk?dl $=0$ ). The students can use the application with completed graphical tasks, both at practice classes and at home. Specifically, if a student missed a step in solving the task, explained by the teaching assistant during the practice classes, he/she could use the application later and complete the graphical task this way.

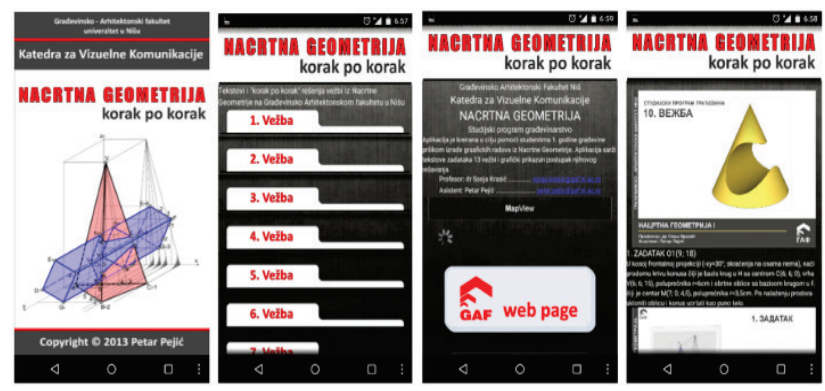

Figure 3 Front and other pages of "step-by-step" Android application (Source: Krasic et al. 2018)

\subsubsection{Advanced Method Practice Classes}

Practice classes were organized by computer designed "step-by-step" graphical tasks, PowerPoint presentations, beamed on the screen. Additional explanations drawn on the blackboard were also available.

The first three advanced methods were available to all the students, while the fourth, named "advanced method practice classes", was available only to the half of the 2014/15 academic year enrolled students ("experimental group"). 
All these methods have been introduced in order to facilitate and enhance the learning process, which was to be shown in the exams, and through other benefits.

\subsection{Comparative Effectiveness Analysis of the Advanced and the Classical Teaching Methods in the 2014/2015 Academic Year}

For this academic year, performed comparative analysis of the exam result encompassed: final results from the test, written part of the examination, examination final grade, and the examination period of the grade obtained in this subject course. All four advanced teaching methods have been used in work with 38 students (experimental group -the EG). Classical teaching methods, with drawings on the blackboard during the practice classes were applied in teaching 41 students (control group -the CG). It is a total of 79 students, due to 11 persons who have left the studies prior to passing the exam [15]. These two groups were formed randomly - based on the first letter of students' surnames, in an alphabetic order. Based on the in-detail data displayed by the charts (Fig. 4), it is concluded that there are better final results achieved by the experimental group of students (86.8\%), compared to the control group (78.1\%). Specifically, the exam pass rate was higher in the EG than in the CG group [15].

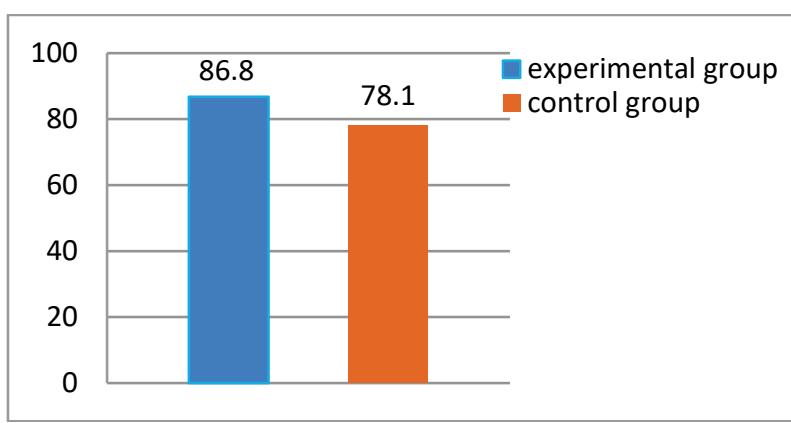

Figure 4 Percentage of students who passed the exam in academic year 2014/15 (Source: Krasic et al. 2016)

\section{EFFECTIVENESS STUDY ON ADVANCED TEACHING METHODS IN DESCRIPTIVE GEOMETRY IN THE ACADEMIC YEAR OF 2016/2017 \\ 3.1 Design and Procedure}

As mentioned above, the introduction of new teaching methods led to the improvement in the DG course final exam results. However, the differences between the group trained traditionally, and the one trained by the innovative way were small, besides -the conducted analysis did not cover all segments of the exam. Moreover, it was not possible to explain the origin of the difference in academic achievements because there were no information on factors that may have been important in learning process. Due to these reasons, a new and more comprehensive study was designed and conducted in 2016/17 academic year.

The aim of this study was to gather more information on the effectiveness of classical and advanced teaching methods than previously obtained, and to examine the role of certain factors that may be of significance in mastering the content of the DG. The authors designed the questionnaire to gather information about student's previous education, average grade indicating level of school achievement, data on whether they have attended the DG course in previous education, and if they have competed in the DG knowledge contests.

At the beginning of the semester, this questionnaire was given to 89 students, who previously gave informed consent for participation in the research.

In order to determine whether advanced teaching methods, in comparison to the traditional ones, lead to better overall results, all the students enrolled at the DG course in the 2016/17 academic year were divided into two groups, the same way as in the previous 2014/15 survey.

By statistical analysis it has been proved that the $\mathrm{E}$ and the $\mathrm{C}$ groups did not differ in regard to aspects that could have been the source of differences in efficacy of learning the DG, namely: a) the previously completed secondary school (gymnasium, or vocational school -engineering, electronic, technical), b) the academic success during schooling, c) attending geometry courses during the previous schooling, d) participation in geometry knowledge competitions.

\subsection{The Role of Spatial and Perceptual Abilities of Students}

Choosing university level studies requires sufficiently developed intellectual capacity of a person. The choice of studying architecture, and/or civil engineering, requires that a person has spatial and perceptual abilities developed particularly well. Therefore, one of this study's goals was to assess the level of intellectual abilities of students, with the expectation that respondents from the experimental and the control groups will be equated in degree of their general and particular intellectual abilities.

The KOG3 [26] test battery, a widely known instrument, was used to measure intellectual abilities of students. It consists of three tests: 1) IT - designed to assess the perceptual abilities of a person, which is the synthesis of the perceptual analysis ability, perceptual structuring, and perceptual identification; 2) Al-4, that is aimed at assessing verbal understanding of a person; 3) S-1, S, aimed to measure the person's ability of visual spatialization, or the ability of a person to visualize spatial relations. KOG3, consisting of 109 items, is a reliable instrument, and besides assessing the specific intellectual abilities mentioned above, it can provide an estimation of General Intelligence and intelligence quotient IQ of a person.

The statistical analysis (from the SPSS package) showed, as in Tab. 2, that the two groups of students (the EC and the CG) did not differ significantly neither in the level of perceptual, verbal and spatial abilities, nor in the level of general intelligence $(t=0.71, p=0.479 ; t=-1.55$, $p=0.125 ; t=-0.81, p=0.421 ; t=-0.66, p=0.508, d f=$ 87 , results were given respectively).

Besides, the results showed the following: students are at $80 \%$ in terms of their spatial abilities, at $70 \%$ in terms of verbal abilities, and at $60 \%$ as to the level of their perceptual abilities. Such results could be expected since they belong to a highly selective sample of students who, according to their abilities, decided to study civil engineering and architecture. Data are in accordance with Holland's [11] theory of career choice which proposed the existence of six professional and vocational types that are related to some personality dispositions. The main idea is 
that person generally chooses the vocation according to his/her professional interests and personality traits. So, students of our research sample have been also choosing their future vocation based on their professional interests and personality dispositions. It is the reason for the experimental and the control group not differing in the level of intellectual abilities.

Table 2 Statistical analysis of perceptual verbal and spatial abilities of students (Source: Krasic et al. 2018)

\begin{tabular}{|c|c|c|c|c|c|c|c|c|}
\hline \multicolumn{9}{|c|}{ Visual perception ability test } \\
\hline & $N$ & Min & Max & Mean & Std. Dev. & $t$ & $d f$ & $p$ \\
\hline $\mathrm{CG}$ & 49 & 6 & 32 & 23.16 & 5.01 & \multirow{2}{*}{0.71} & \multirow{2}{*}{87} & \multirow{2}{*}{0.479} \\
\hline$\overline{E G}$ & 40 & 4 & 34 & 22.3 & 5.77 & & & \\
\hline \multicolumn{9}{|c|}{ Verbal perception ability test } \\
\hline & $N$ & Min & Max & Mean & Std. Dev. & $t$ & $d f$ & $p$ \\
\hline $\mathrm{CG}$ & 49 & 10 & 39 & 29.96 & 6.39 & \multirow{2}{*}{-1.55} & \multirow{2}{*}{87} & \multirow{2}{*}{0.125} \\
\hline EG & 40 & 14 & 40 & 32.00 & 5.92 & & & \\
\hline \multicolumn{9}{|c|}{ Spatial ability test } \\
\hline & $N$ & Min & Max & Mean & Std. Dev. & $t$ & $d f$ & $p$ \\
\hline $\mathrm{CG}$ & 49 & 10 & 30 & 23.39 & 5.16 & \multirow{2}{*}{$-0,81$} & \multirow{2}{*}{87} & \multirow{2}{*}{0,421} \\
\hline$\overline{E G}$ & 40 & 5 & 30 & 24.33 & 5.76 & & & \\
\hline
\end{tabular}

What conclusion based on analysis conducted here could be made? Since there were no differences between $\mathrm{E}$ and $\mathrm{C}$ group of students in regard to: their spatial and perceptual abilities, previous education, attendance of the DG course during secondary schooling, etc., it is clear that any differences in percentages of students who will pass the Descriptive geometry final exam, as well as the differences in the indicators of successful learning, such as final grade and so on, could be attributed to the factor of being subject to the advanced or to the classical methods of teaching!

\subsection{Comparative Effectiveness Analysis of Advanced and Classical Teaching Methods in the 2016/2017 Academic Year}

Comparative analysis was performed on all the results, both the input data and the final exam results, obtained in these two groups, namely the experimental (the EG - 40) and the control one (the CG - 49). It was not the total number of 95 students enrolled who were included, because 6 of them have left the studies prior to passing the exam. The author's assumption is that all four advanced teaching methods would provide for better results, that is higher exam pass rate, and better average grades.

\subsection{Final Exam Results \\ 3.4.1 Test Results}

The test was done at half of the course and was worth 10 points. The test contains 10 tasks related to the basic concepts and procedures of the DG course, and it was taken only once. The average number of points in the $\mathrm{E}$ group of students is 7.46 , while the average number of points of the $\mathrm{C}$ group of students is 6.52 . If the test results are compared, the difference is statistically significant - in favour of the E group (Tab. 3).

Table 3 Statistical analysis of test results (Source: Krasic et al. 2018)

\begin{tabular}{|c|c|c|c|c|}
\hline & $N$ & Mean & $t$ statistic & $p$ \\
\hline CG & 49 & 6.52 & -2.10 & 0.039 \\
\hline EG & 40 & 7.46 & & 0.039 \\
\hline
\end{tabular}

\subsubsection{Results of the Written Part of the Examination}

The written part of the examination is performed at the end of the course, and carries a total of 60 points. The written part of the examination consists of 4 tasks, which cover all the areas previously taught at the lectures and practice classes. In this case, the negligible difference in average points is in favour of the E group of student (Tab. 4). This time again, advanced method exercises yielded much better results than the classical ones.

Table 4 Statistical analysis of results of written part of examination (Source: Krasic et al. 2018)

\begin{tabular}{|c|c|c|c|c|}
\hline & $N$ & Mean & $t$ statistic & $p$ \\
\hline CG & 34 & 39.38 & -1.27 & 0.210 \\
\hline EG & 33 & 42.52 & -12 & \\
\hline
\end{tabular}

\subsubsection{Final Exam Grades}

The analysis of the final exam grades did include all consecutive examination periods in the academic year when the course was conducted. If the average of exam grades is compared, the difference is negligible, but in favour of the E group of students (Tab. 5). The average grade is, in all examination periods, higher in the E group relative to $\mathrm{C}$ group of students (Fig. 5). It can be concluded that students who had used all four advanced teaching methods in all the examination periods have achieved a better average grade.

Table 5 Statistical analysis of final exam grades (Source: Krasic et al. 2018)

\begin{tabular}{|c|c|c|c|c|}
\hline & $N$ & Mean & $t$ statistic & $p$ \\
\hline CG & 34 & 7.91 & -1.35 & 0.182 \\
\hline EG & 33 & 8.33 & & \\
\hline
\end{tabular}

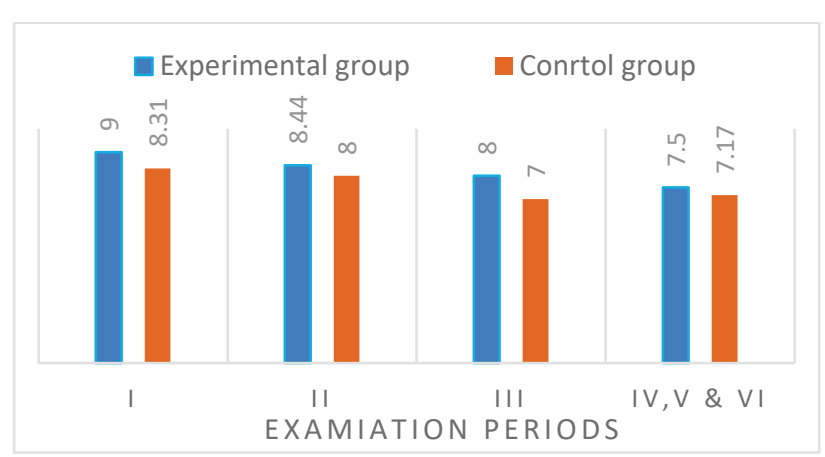

Figure 5 Final exam grades (Source: Krasic et al. 2018)

\subsubsection{Examination Periods Results}

If we compare number and the results that the students who mastered the final exam have achieved in the individual examination periods, it can be seen that the period-bound results are rather balanced. A small difference occurs in the $1^{\text {st }}$ examination period, in favour of the E group $(27.5 \%)$ in comparison with the $\mathrm{C}$ group $(26.5 \%)$. A higher difference in exam pass rate occurred in the $3^{\text {rd }}$ examination period, in favour of E group $(12.5 \%)$ in comparison with the C group (4.1\%) (Tab. 6).

The pass rate, namely the percentage of the students who did pass the exam during the academic year (Fig. 6) is higher in the E group (82.5\%), then in the $\mathrm{C}$ group (69.4\%).

Number of students who mastered the final result is larger in the E group (Fig. 6), that is students in advanced 
method practice classes, than in group attending classical method practice classes.

Table 6 Statistical analysis of examination periods results (Source: Krasic et al. 2018)

\begin{tabular}{|c|c|c|c|c|c|c|c|c|c|}
\hline & & ia & $\underset{1}{\stackrel{N}{c}}$ & in & 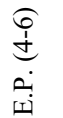 & $\stackrel{\pi}{0}$ & 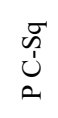 & $d f$ & $p$ \\
\hline \multirow{2}{*}{ CG } & No & 13 & 13 & 2 & 6 & 49 & \multirow{4}{*}{4.51} & \multirow{4}{*}{4} & \multirow{4}{*}{0.34} \\
\hline & $\%$ & 26.5 & 26.5 & 4.1 & 12.2 & 100.0 & & & \\
\hline \multirow{2}{*}{ EG } & No & 11 & 9 & 5 & 8 & 40 & & & \\
\hline & $\%$ & 27.5 & 22.5 & 12.5 & 20.0 & 100.0 & & & \\
\hline
\end{tabular}

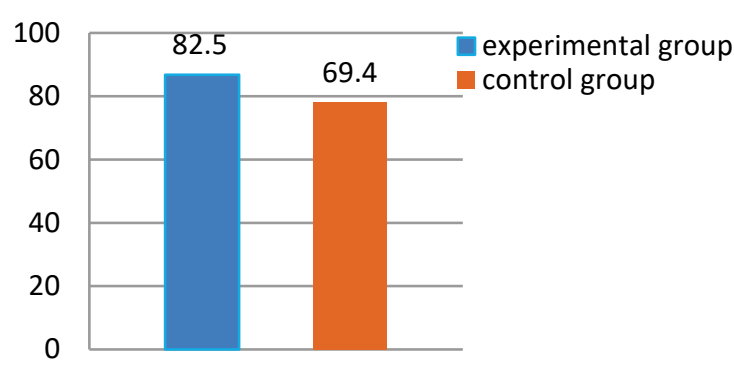

Figure 6 Percentage of students who passed the exam in 2016/17 academic year (Source: Krasic et al. 2018)

\section{STUDENT'S EVALUATION OF ADVANCED TEACHING METHODS}

The survey for evaluation of the DG subject course was designed by the authors of this paper. Questions are divided into 3 groups:

1) Teaching methods -this survey block contains 9 questions concerning the content of the subject course, and the evaluation of teaching methods demonstrated by the professor and the teaching assistant

2) "Step-by-step" presentation of graphical tasks - this survey block contains 4 questions concerning helpfulness of the presentations for the student's work, at class and home

3) "Step-by-step" Android application of graphical tasks - this survey block contains 4 questions concerning helpfulness of the Android application for the student's work at class and home.

After completing the DG course, an anonymous questionnaire for evaluating the subject was conducted in both groups, E (34) and C (41), namely total of 75 students. That is $3 / 4$ of the total number of students enrolled (95), hence the survey results are valid.

The questionnaire responses got analysed and presented so as to match the respective groups of questions.

\subsection{Teaching Methods Questionnaire Evaluation}

The first group of questions assessed the teaching methods. Tab. 3 shows the results with students evaluating the work of professors and teaching assistants on scale 15.

The table shows the average grades of students' rating for teaching methods. The attached table points out the conclusion that students in the E group are more satisfied with the teaching. The highest average grade in the E group is scored on question No. 8 (4.80). It can be concluded that the work of teaching assistants is aided by their use of the presentations, and thus more time is spent on additional explanations and the individual work with students. This is confirmed by the average grades rating questions No. 5 (4.68), and No. 6 (4.68), which are directly related to question No. 8. In the C group, question No. 1 (4.32) has scored the highest average mark. This is of great significance for the author's team, because the students have noticed that the material for lecturers is well connected with the material for practice classes. The lowest average grade in both, the $\mathrm{E}$ and the $\mathrm{C}$ group was given to question No. 3 (3.44 in the EG, and 3.20 in the CG).

Table 3 Teaching questionnaire evaluation (Source: Krasic et al. 2018)

\begin{tabular}{|c|l|c|c|}
\hline No. & \multicolumn{1}{|c|}{ Question (grades 1-5) } & EG & CG \\
\hline 1. & $\begin{array}{l}\text { Compliance of materials in lectures and } \\
\text { practice classes }\end{array}$ & 4.18 & 4.32 \\
\hline 2. & $\begin{array}{l}\text { Compliance of the tempo of lectures / practice } \\
\text { classes with the fond of classes }\end{array}$ & 3.77 & 3.56 \\
\hline 3. & $\begin{array}{l}\text { How much the lectures helped in the } \\
\text { preparation of graphical tasks }\end{array}$ & 3.44 & 3.20 \\
\hline 4. & Clarity and style of professor's presentation & 4.03 & 3.60 \\
\hline 5. & $\begin{array}{l}\text { How much practice classes helped in the } \\
\text { preparation of graphical tasks }\end{array}$ & 4.68 & 3.85 \\
\hline 6. & $\begin{array}{l}\text { Clarity and style of teaching assistant } \\
\text { presentation }\end{array}$ & 4.68 & 3.95 \\
\hline 7. & $\begin{array}{l}\text { Correctness in communication with students, } \\
\text { professionalism and ethics of professors }\end{array}$ & 4.65 & 4.21 \\
\hline 8. & $\begin{array}{l}\text { Correctness in communication with students, } \\
\text { professionalism and ethics of teaching } \\
\text { assistant }\end{array}$ & 4.80 & 4.12 \\
\hline 9. & $\begin{array}{l}\text { Methods and procedures for evaluating pre- } \\
\text { exam obligations }\end{array}$ & 4.38 & 4.24 \\
\hline
\end{tabular}

Students in both groups considered that lectures did not help much in the preparation of graphical tasks. Lectures are carried out by classical methods, the solution to the problem being given gradually with drawing on the blackboard. A lot of time is being spent on professor's templates drawing for tasks, which are already available to students. The authors of the paper standing is that the lectures can be modernized, the same way as with practice classes - through applying advanced method. Accuracy, size and the possibility of returning through steps is also of great importance to the drawings in lectures as in practice classes.

\subsection{Questionnaire Evaluation for "Step-By-Step" Presentations of Graphical Tasks on the Website of the Faculty}

In the second group of questions, students evaluate how useful for them are "step by step" presentations, during practice classes and for work at home, for how many graphical tasks (more or less than half) did they use, and what grade would they give it on scale1-5.

In regards to usage of the "step-by-step" presentation at practice classes in the E group, $100 \%$ of students have used presentations because the practice classes organized were using them. In the $\mathrm{C}$ group, $32 \%$ of students used presentations via a mobile phone, because it was possible to use them that way. A large number of students in both groups used "step by step" presentation (EG-99\% and CG$83 \%$ ) at home. In both groups, greater number of students used "step by step" presentations for more than half of the 
graphic tasks (EG-82\%, and CG-71\%). The average grade on usefulness of "step-by-step" presentation is better in the E group (4.68), compared with C group (4.07). This shows that students in advanced method practice classes are more satisfied. The difference in average grades is statistically negligible and shows that, for both groups of students, the "step by step" presentations were very useful for work at practice classes, and at home.

\subsection{Questionnaire Evaluation for "Step-By-Step" Android Application of Graphical Tasks}

In the third group of questions, students evaluated how useful the "step by step" Android application was for them, using the same set of questions as in the 4.2 section. Considering that, at the practice classes in the E group, "step by step" presentations were used, just over half of the students used the Android application for graphical tasks too. Compared to the E group, there is higher percentage of students in the $\mathrm{C}$ group who have used the Android application both at practice classes and at home. The author's opinion is that such situation is the consequence of the classical teaching method use. In both groups of students, Android applications have been used for more than half of the graphical tasks. The average grade by students for the usefulness of the "step-by-step" Android application is better in the E group (4.18), compared with the $\mathrm{C}$ group score (3.92). Android application usage rate is lesser than usage rate of presentations on the Faculty web site. This result can be explained by the fact that not all students have smart mobile devices.

\section{CONCLUSION}

The paper presents the benefits of using advanced teaching methods in the DG course at the FCEA in Niš. From the 2009/2010 academic year, the usage of AutoCAD, and Corel Draw software for drawings in lecture templates, "step by step" presentations, and "step by step" Android application, facilitated prompted mastering of the course subject matter, and enhanced teaching quality. All the material contained the classical didactic approach principle. Accuracy, size, and possibility of moving back and forth through the steps are all of great importance to the drawings in lectures and practice classes. Moreover, for modernizing teaching process, internet networks and smart mobile devices have been used, as media through which teaching materials were available to all students. All the advanced teaching methods introduced in this course in period from 2009/2010 to 2016/2017 have influenced an increased final score of all students. The benefits of using these advanced methods are that the work is easier, and more time can be devoted to additional explanations and individual work with students, which results in upgrading student's visual perception. Such advanced teaching methods could be introduced into lectures, by the author's recommendation, which will be the subject of further research.

\section{REFERENCES}

[1] Căuneac, D., Chiliban, B., \& Chiliban, M. (2014). Modern educational instruments and blended-learning technologies in descriptive geometry teaching. The $5^{\text {th }}$ International Conference on Engineering and Business Education (ICEBE2014), Sibiu, Romania, 1-4. https://doi.org/10.2478/cplbu-2014-0109

[2] Clivel, D., Alicem, A., Ozgureris, Danield, F., \& Larryj, L. (2005). Engineering Design Thinking, Teaching, and Learning. Journal of Engineering Education, 103. https://doi.org/10.1002/j.2168-9830.2005.tb00832.x

[3] Chu, M. H., Jeng, T. S., \& Chen, C. H. (2015). Itouying: A serious game for learning orthographic projection. International Journal on New Trends in Education and Their Implications, 6(3), Article: 15, 148-164.

[4] Di Paola, F., Pedone, P., \& Pizzurro, M. R. (2013). Digital and interactive Learning and Teaching methods in descriptive geometry. Proceedings of $4^{\text {th }}$ International Conference on New Horizons in Education, Education and Technology-TASET, Sakarya Universitesi, Turkey, 873-885. https://doi.org/10.1016/j.sbspro.2013.12.100

[5] García, R. R., Quirós, J. S., Santos, R. G., González, S. M., \& Fernanz, S. M. (2007). Interactive multimedia animation with Macromedia Flash in Descriptive Geometry Teaching. Computers \& Education, 49(3), 615-639. https://doi.org/10.1016/j.compedu.2005.11.005

[6] Gittler, G. (1994). Intelligenzförderung durch Schulunterricht: Darstellende Geometrie und räuumliches Vorstellungsvermögen. In Gittler G., editor, Die Seele ist ein weites Land, Wiener Universitätsverlag, Wien, 105-122.

[7] Gittler, G. \& Gluck, J. (1998). Differential Transfer of Learning: Effects of Instruction in Descriptive Geometry on Spatial Test Performance. JGG, 2(1), 71-84

[8] Gorjanc, S., Halas, H., \& Jurkin, E. (2014). Introducing 3D Modeling into Geometry Education at Two Technical Faculties at the University of Zagreb. $16^{\text {th }}$ International Conference on Geometry and Graphics ISGG, 4-8 August, 2014, Innsbruck, Austria, 2-9.

[9] Gutierrez, J. M., Gil, F. A., Contero, M., \& Saorin, J. L. (2013). Dynamic Three-Dimensional Illustrator for Teaching Descriptive Geometry and Training Visualisation Skills. Computer Applications in Engineering Education, 21(1), 8-25. https://doi.org/10.1002/cae.20447

[10] Hohne, G. \& Henkel, V. (2004). Application of multimedia in engineering design education. European Journal of Engineering Education, 29(1), 87-96. https://doi.org/10.1080/0304379032000129278

[11] Holland, J. L. (1997). Making vocational choices: A theory of vocational personalities and work environments. Odessa, F. L.: Psychological Assessment Resources, Inc.

[12] Juodagalvien, B. \& Vdovinskien, S. (2011). Aspects of modernization of teaching Engineering Graphics. Proceedings BALTGRAF-11, Tallinn University of Technology Centre of Engineering Graphics, 29-35.

[13] Lee, C. K. \& Basant Singh, M. S. (2015). Engineering Students Learning Preferences in UNITEN: Comparative Study and Patterns of Learning Styles. Journal of Educational Technology \& Society is available under Creative Commons, 266-282.

[14] Krasic, S., Pejić, P., \& Krstić, H. (2015). Implementation of Contemporary Methods in Teaching Descriptive Geometry at the Faculty of Civil Engineering and Architecture of Niš. Book of abstracts, $18^{\text {th }}$ Scientific-Professional Colloquium on Geometry and Graphics, Croatia, 21-22.

[15] Krasić, S., Pejić, P., \& Veljković, M. (2016). A Comparative analysis of Contemporary and Classical Teaching methods of Descriptive geometry at the Faculty of Civil Engineering and Architecture in Niš. Book of abstracts, Proceedings of International scientific conference moNGeometrija 2016, 43-45.

[16] Klix, W. D. (2001). Konstruktive Geometrie, darstellend und analytisch. Fachbuchverlag, Graphics and Descriptive Geometry, Tokyo, 533-535. 
[17] Mohler, L. J. (2008). A Review of Spatial Ability Research. Engineering Design Graphics Journal, 72(3), 19-30.

[18] Morales, M. P., Penin, P. A., Sevillano, A. P., \& Cerra, P. P. (2009). Design and Use of a Multimedia Trainer for the Subject Descriptive Geometry. Computer Applications in Engineering Education, 17(1), 13-24. https://doi.org/ 10.1002/cae.20164

[19] Pedrosa, C. M., Barbero, B. R., \& Miguel, A. M. (2014). Spatial Visualization Learning in Engineering: Traditional Methods vs. a Web-based Tool. Educational Technology \& Society, 17(2), 142-157.

[20] Rubio, L., Abella, B. M., Castejon, C., \& Sanchez, A. M. (2010). Web-Based Application for Descriptive Geometry Learning. Computer Applications in Engineering Education, 18(3), 574-581. https://doi.org/10.1002/cae.20244

[21] Sorby, S. S. (1999). Developing 3-D Spatial Visualization Skills. Engineering Design Graphic Journal, 63(2), 21-32.

[22] Stachel, H. (2005). Descriptive Geometry in today's engineering curriculum. Trans FAMENA, 29, 1-4. www.geometrie.tuwien.ac.at/stachel/zagreb.pdf

[23] Stachel, H. (2007). The status of today's Descriptive Geometry related education $(\mathrm{CAD} / \mathrm{CG} / \mathrm{DG})$ in Europe. Annual Meeting of JSGS, $40^{\text {th }}$ anniversary of Japan Society for Graphic Science, Japan, Tokyo, 15-20. https://doi.org/10.5989/jsgs.41.Supplement1_15

[24] Stavrić, M., Wiltsche, A., \& Schimek, H. (2005). New Dimension in Geometrical Education Methods of Representation Course - New Media. Classical Construction, Geometrical Freehand Drawing, KoG 9, 4554.

[25] Veide, Z., Strozheva, V., \& Veide, G. (2014). Manual Drawing in Modern Engineering education. Joint International Conference on Engineering Education \& International Conference on Information Technology, ICEE/ICIT-2014, June 2 - 6, Riga, Latvia, 25-28.

[26] Wolf, B., Momirović, K., \& Džamonja, Z. (1992). KOG 3. Baterija testova inteligencije. Beograd: SDPS - Centar za primenjenu psihologiju.

\section{Contact information:}

Sonja KRASIĆ, PhD, Associate Professor

(Corresponding author)

Faculty of Civil Engineering and Architecture,

University of Niš,

Aleksandra Medvedeva 14, 18000 Niš, Serbia

krasic.sonja@gmail.com

Petar PEJIĆ, PhD student

Faculty of Technical Science,

University of Novi Sad,

Trg Dositeja Obradovica 6, 21000 Novi Sad, Serbia

petarpejic@i.ua

Snežana STOJILJKOVIĆ, PhD, Full Professor

Faculty of Philosophy,

University of Niš

Ćirila i Metodija 2, 18000 Niš, Serbia

snezana.stojiljkovic@filfak.ni.ac.rs

Mila DOSKOVIĆ, Assistant, PhD student

Faculty of Philosophy,

University of Niš,

Ćirila i Metodija 2, 18000 Niš, Serbia

mila.doskovic@filfak.ni.ac.rs

Zlata TOŠı́, PhD student

(Corresponding author)

Faculty of Civil Engineering and Architecture,

University of Niš,

Aleksandra Medvedeva 14, 18000 Niš, Serbia

zlata10@live.com 